\title{
Monte Carlo Simulations on the Relation between the Structure and Propertles of Zeolltes: The Adsorption of Small Hydrocarbons
}

\author{
B. Smit* and C. J. J. den Ouden \\ Koninklijke/Shell Laboratorium, Amsterdam (Shell Research B.V.), Badhuisweg 3, 1031 CM Amsterdam, \\ The Netherlands (Received: September 6, 1988)
}

\begin{abstract}
In order to understand the high selectivities observed in adsorption processes and catalytic conversions of hydrocarbons using zeolites, it is necessary to study the behavior of molecules inside the pores of a zeolite. This kind of information is difficult to obtain from direct experiments. We report Monte Carlo computer simulations on the adsorption of methane in the zeolites faujasite, mordenite, and ZSM-5. For all compounds our simulations yield good agreement with the available experimental data on the heat of adsorption. In addition, the present calculations predict that the heat of adsorption of methane in mordenite should decrease steeply with increasing $\mathrm{Al} / \mathrm{Si}$ ratio. Analysis of the distribution of $\mathrm{CH}_{4}$ in mordenite suggests a simple explanation for this peculiar effect, which may appear to be of great importance for the catalytic activity of mordenite.
\end{abstract}

Living organisms, employing enzymes, can synthesize molecules with essentially $100 \%$ selectivity. Compared to this elegance, chemical reactions in the process industries are rather crude ways of producing useful chemicals. However, recent improvements in the design of zeolite catalysts suggest that much higher selectivities may be achieved in the near future. ${ }^{1}$

Zeolites are microporous crystalline materials usually consisting of silicon, aluminum, oxygen, and sodium. Certain positions on the inner walls of the micropores appear to behave as active sites, where catalytic conversions can take place. Selectivity can be obtained by adjusting the size of the micropores or cavities and by modifying the location of the active sites in such a way that, ideally, only one type of molecular species can reach these active sites. Of course, the performance of currently available zeolites is still far removed from this "enzyme-like" selectivity, but it is clear that a better understanding of the microscopic basis for the catalytic action of zeolites may help us approach this ultimate goal of zeolite chemistry. One of the first factors that must be understood is the relation between the molecular structure of a zeolite and the adsorption of specific molecules. One particularly promising tool to obtain such information is computer simulation..$^{2-5}$

Recently, Yashonath et al. ${ }^{2}$ have reported a simulation study on the adsorption of methane in faujasite, with emphasis on the influence of the temperature on the adsorption. In this work we have used the methods pioneered by Yashonath et al. ${ }^{2}$ to gain a better understanding of the effect of the chemical composition of mordenite, which is indicated by the $\mathrm{Al} / \mathrm{Si}$ ratio, on the adsorption process. The latter parameter is known to have a pronounced effect on the catalytic activity of zeolites. ${ }^{6}$

We have carried out simulations at low coverage of methane (zero filling). This allows us to ignore methane-methane interactions. In our simulations (cf. Table I for the structural information on the zeolites) both the zeolite and the methane molecule are assumed to be rigid. With these assumptions the potentials contain only methane-zeolite interactions, which are represented as a sum of pairwise-additive terms ${ }^{7}$

$$
U=\sum_{i} \sum_{j} \Phi_{i j}
$$

where the summation runs over all the atoms of the adsorbate and the zeolite. Following Kiselev et al. ${ }^{7}$ and Yashonath et al. ${ }^{2}$

(1) Csicsery, R. M. Pure Appl. Chem. 1986, 58, 641.

(2) Yashonath, S.; Thomas, J. M.; Nowak, A. K.; Cheetham, A. K. Nature (London) 1988, 331, 601.

(3) Demontis, P.; Suffritti, G. B.; Quartieri, S.; Fois, E. S.; Gamba, A. J. Phys. Chem. 1988, 92, 867 .

(4) Suto, J. L.; Myers, A. L. Mol. Phys. 1981, 42, 971

(5) Derouane, E. G.; Andre, J. M.; Lucas, A. A. Chem. Phys. Lett. 1987 $137,336$.

(6) Mirodatos, C.; Barthomeuf, D. J. Catal. 1985, 93, 246.

(7) Kiselev, A. V.; Lopatikin, A. A.; Schulga, A. A. Zeolites 1985, 5, 261.
TABLE I: Structural Information on the Zeolites Considered in This Paper

\begin{tabular}{|c|c|c|c|c|}
\hline zeolite & $\begin{array}{c}\text { lattice } \\
\text { parameters, } \AA\end{array}$ & $\begin{array}{c}\text { unit cell compn } \\
\left(\mathrm{Na}_{x} \mathrm{Al}_{x} \mathrm{Si}_{(y-x)} \mathrm{O}_{2 y}\right)\end{array}$ & space group & ref \\
\hline faujasite & $\begin{array}{l}a=24.92 \\
b=24.92 \\
c=24.92\end{array}$ & $\begin{array}{l}y=192 \\
x=48\end{array}$ & $F d 3 m$, no. 227 & 9 \\
\hline mordenite & $\begin{array}{l}a=18.33 \\
b=20.72 \\
c=7.60\end{array}$ & $\begin{array}{l}y=48 \\
x=0-16\end{array}$ & $\mathrm{CmCm}$, no. 63 & 10 \\
\hline ZSM-5 & $\begin{array}{l}a=20.07 \\
b=19.92 \\
c=13.42\end{array}$ & $\begin{array}{l}y=96 \\
x=0\end{array}$ & Pnma, no. 62 & 11 \\
\hline
\end{tabular}

TABLE II: Lennard-Jones Parameters and Atomic Charges ${ }^{2,7}$ (in atomic units)

\begin{tabular}{|c|c|c|c|c|}
\hline \multirow[b]{2}{*}{ adsorbent } & \multicolumn{2}{|c|}{$A, \mathrm{~kJ} /\left(\mathrm{mol} / \AA^{-6}\right)$} & \multicolumn{2}{|c|}{$B, \mathrm{~kJ} /\left(\mathrm{mol} / \AA^{-12}\right)$} \\
\hline & zeolite $\mathrm{O}$ & zeolite $\mathrm{Na}$ & zeolite $\mathrm{O}$ & zeolite $\mathrm{Na}$ \\
\hline $\mathrm{C}$ & 1715.9 & 554.7 & 1016900 & 698500 \\
\hline \multirow[t]{3}{*}{$\mathrm{H}$} & 580.2 & 169.6 & 111800 & 75800 \\
\hline & adsorbent & \multicolumn{3}{|c|}{ zeolite } \\
\hline & $\mathrm{C}$ & $\mathrm{Na}$ & $\operatorname{Si}(A \mid)$ & $\mathrm{O}$ \\
\hline charge & 0.07 & 1.0 & $2 q_{o}-(x / y)$ & -0.7 \\
\hline
\end{tabular}

we assume that $\Phi_{i j}$ can be written as the sum of a Lennard-Jones potential and a Coulombic interaction

$$
\Phi_{i j}=\left[B_{i j} / r_{i j}^{12}\right]-\left[A_{i j} / r_{i j}^{6}\right]+\left[q_{i} q_{j} / r_{i j}\right]
$$

where $q_{i}$ is the charge of atom $i$ and $r_{i j}$ the distance between the atoms $i$ and $j$. The values of $A_{i j}, B_{i j}$, and $q_{i}$ are give in Table II. Note that owing to the small size and polarizability of the silicon and aluminum atoms, their contribution to the Lennard-Jones potential can be neglected. ${ }^{2,7}$ In our calculations we have assumed that the charges on the oxygen and sodium ions are constant. The charges on the silicon and aluminum ions are assumed to be equal and follow from the requirement that the total charge of the zeolite is zero.

The Monte Carlo calculations were performed using the conventional Metropolis algorithm. ${ }^{8}$ A methane molecule is initially placed inside a micropore of the zeolite. One Monte Carlo step consists of two parts: first a random displacement of the center of mass followed by an arbitrary rotation of the entire molecule. In order to eliminate the effect of boundaries we have used periodic boundary conditions with a period equal to one zeolite unit cell. Furthermore, in order to save computer time, the potentials are truncated at a cutoff radius which is of the order of the size of

(8) Metropolis, N.; Rosenbluth, A. W.; Rosenbluth, M. N.; Teller, A. H.; Teller, E. J. Chem. Phys. 1953, 2l, 108i. 


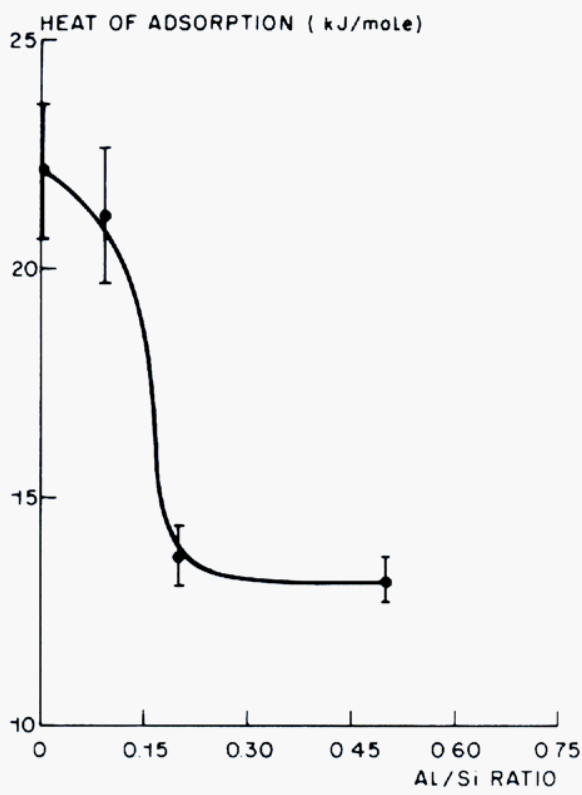

Figure 1. Heat of adsorption of methane in mordenite as a function of the $\mathrm{Al} / \mathrm{Si}$ ratio. The line serves as a guide to the eye.

one unit cell. In order to make an estimate of the statistical reliability, the simulations were divided into subruns of 10000 Monte Carlo steps each. The listed standard deviations were obtained from these subruns. One total run took from 10 up to 20 subruns.

As a test of the quality of the intermolecular potential (eq 2), we computed the heat of adsorption of $\mathrm{CH}_{4}$ in various zeolites. In Table III our simulation results are compared with experimental data and with the results of Yashonath et al. ${ }^{2}$ In all cases, there

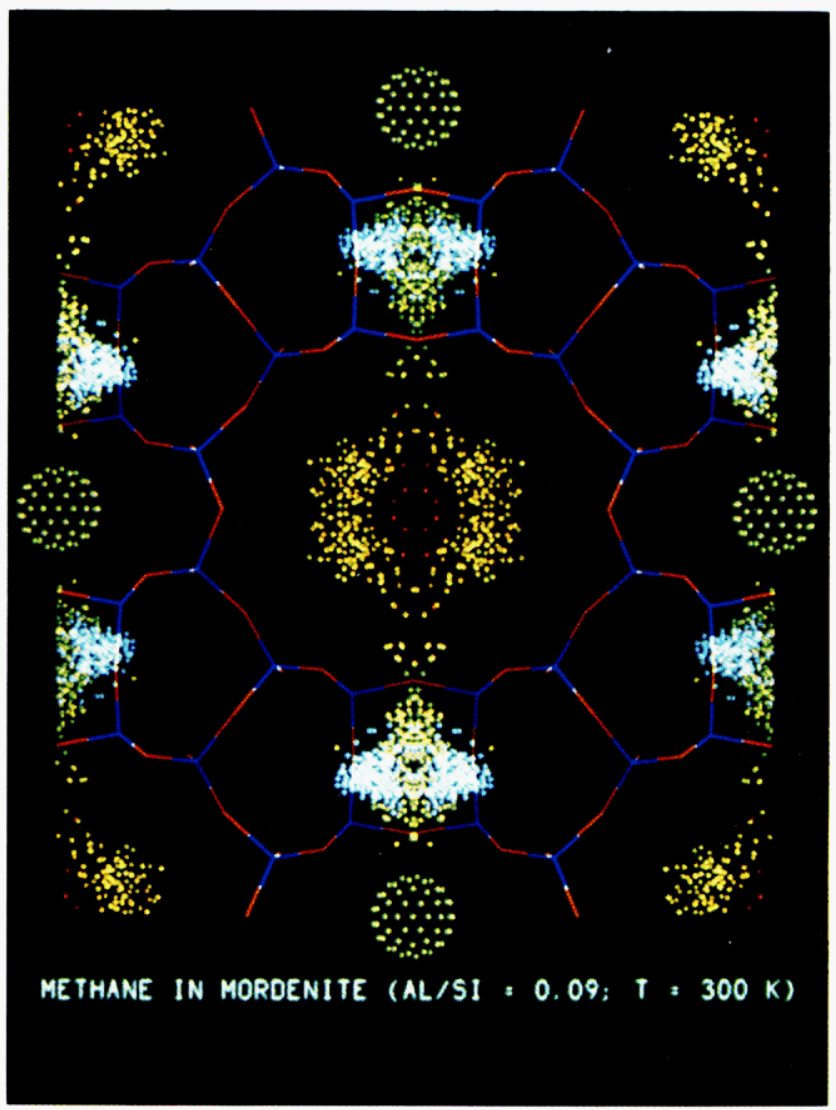

is essentially quantitative agreement between the experimental and numerical data, considering the estimated error in the experimental and computational data. As can be seen in Table III, the heat of adsorption increases as the size of the pores of the zeolite decreases. This is not surprising because a smaller pore size facilitates the interactions of methane with the pore walls. This results in a higher heat of adsorption (cf. zeolite ZSM-5). It is therefore somewhat surprising to find that, for mordenite, which has a rather large pore diameter ( $7 \AA$ ), the experimental and the calculated heats of adsorption are much higher than for faujasite $(8 \AA)$. In the following paragraphs we will show that this particular behavior has a simple structural explanation.

In our model we assume that $\mathrm{CH}_{4}$ feels the same interaction due to $\mathrm{Si}$ and $\mathrm{Al}$ atoms in the zeolite. However, as the $\mathrm{Al} / \mathrm{Si}$ ratio is increased the positive charge on the zeolite lattice decreases. This decrease is compensated by sodium ions, which are not located on lattice sites. In Figure 1 the calculated heat of adsorption of methane in mordenite is presented for various $\mathrm{Al} / \mathrm{Si}$ ratios. A sudden decrease of the heat of adsorption can be observed as the $\mathrm{Al} / \mathrm{Si}$ ratio exceeds 0.15 .

The distribution of positions occupied by methane in mordenite is shown in Figure 2. At a low $\mathrm{Al} / \mathrm{Si}$ ratio (Figure $2 \mathrm{a}$ ) we see that methane is located in the straight channels and in the so-called "side pockets", which are situated at the edges of the channels. The color coding in Figure 2a shows that methane located in such a side pocket has a considerably lower energy than a methane molecule in the central channel. As the $\mathrm{Al} / \mathrm{Si}$ ratio is increased, these side pockets are effectively blocked by the sodium ions (Figure 2b). Methane cannot reach these low-energy sites anymore. We suggest that this effective blocking by the sodium ions explains the observed decrease of the heat of adsorption at high $\mathrm{Al} / \mathrm{Si}$ ratios (cf. Figure 1).

It should be stressed that our use of the periodic boundary conditions overemphasizes the regularity of the positions at which sodium ions are to be found. Once we put a sodium ion at a

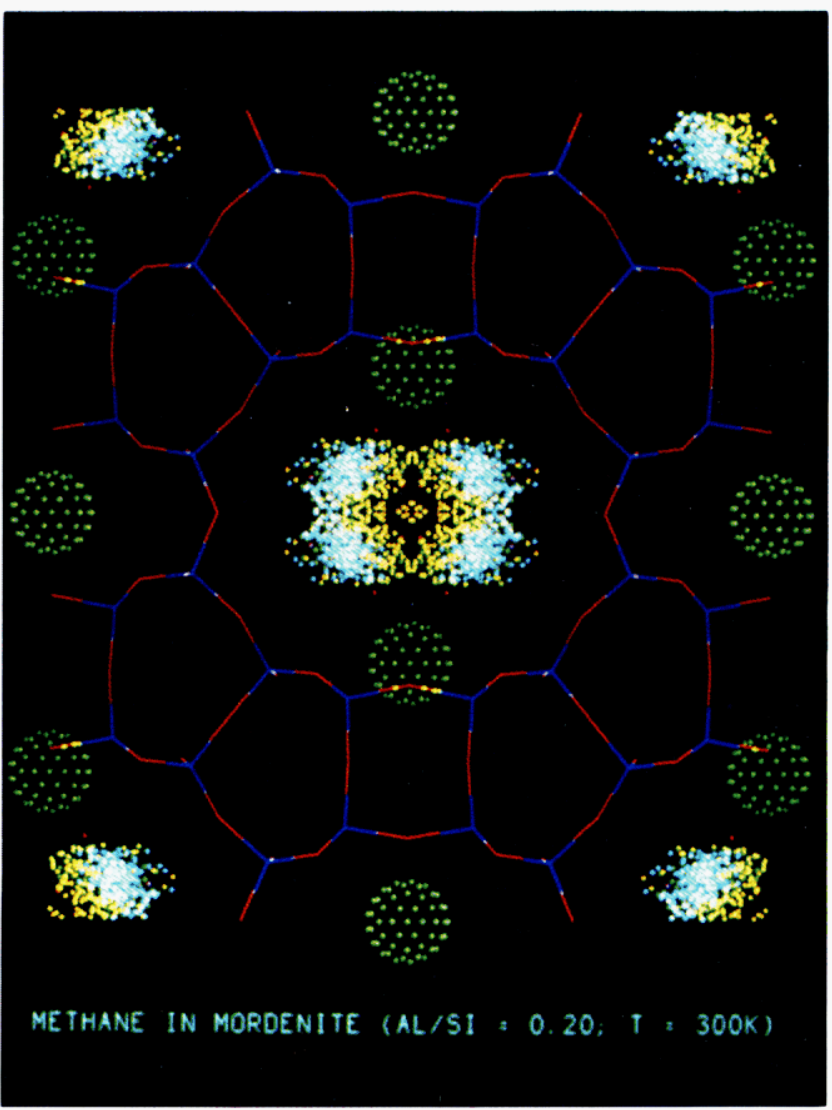

Figure 2. Distribution of methane adsorbed in mordenite at $300 \mathrm{~K}$ and Al/Si $=0.09$ (a, left) and $\mathrm{Al} / \mathrm{Si}=0.2$ (b, right) as obtained by Monte Carlo calculations. The zeolite structure is represented by oxygen (red rods), aluminum and silicon (blue rods), and sodium ions (green spheres). Each spot inside the zeolite pore represents the projection of the center of mass of the methane molecule. The color of the spot is a measure for the energy of the methane molecule (the energy decreases in the order red, yellow, green, green/white). 
TABLE III: Heats of Adsorption $\left(Q_{\mathrm{s}}\right)$ of Methane on Various Zeolites $(\mathrm{kJ} / \mathrm{mol})$

\begin{tabular}{|c|c|c|c|c|c|c|}
\hline zeolite & $\mathrm{Al} / \mathrm{Si}$ & $T, \mathrm{~K}$ & exptl & caled & pore size, $\AA$ & ref \\
\hline \multirow[t]{2}{*}{ faujasite } & 0.33 & 300 & 15.2 & $\begin{array}{l}14.1 \pm 0.4 \\
(13.8)^{a}\end{array}$ & 8 & 12 \\
\hline & 0.00 & 300 & & $15.4 \pm 0.4$ & & \\
\hline \multirow[t]{2}{*}{ mordenite } & 0.09 & 300 & 23.0 & $21.4 \pm 2.6$ & 7 & 13 \\
\hline & 0.00 & 300 & & $22.2 \pm 1.9$ & & \\
\hline ZSM-5 & 0.00 & 300 & 28.0 & $22.3 \pm 0.4$ & 5.5 & 14 \\
\hline
\end{tabular}

particular point in the unit cell, the periodic boundary conditions generate a zeolite structure in which all equivalent sites are occupied by sodium ions. In real zeolites on expects that sodium ions are distributed over several nonequivalent sites. In our calculations it turned out that as the $\mathrm{Al} / \mathrm{Si}$ ratio is increased "simultaneously" all side pockets are blocked. It is more realistic to assume that more gradually side pockets will be blocked. We therefore expect that a more gradual transition from a high value to a low value of the heat of adsorption will be observed. However, thus far the relevant experimental data are lacking.

On the basis of the above observation, we can now explain the relatively high value of the experimental heat of adsorption of methane in mordenite as compared to faujasite (cf. Table III). Although mordenite has a pore diameter $(7 \AA)$ which is not too

(9) Hseu, T. Ph.D. thesis, University of Washington, University Microfilms no. 73-13835, Ann Arbor, MI, 1972.

(10) Meier, W. M. Z. Kristallogr. 1961, 115, 439

(11) Baerlocher, C. Proc. 6th Int. Zeolite Conf. 1983.

(12) Nowak, A. K.; Cheetham, A. K. Proc. 7 th Int. Zeolite Conf. 1986, 475 .

(13) Barrer, R. M. Zeolites: Science and Technology; NATO ASI Series E no. 80; Martinus Nijhoff: The Hague, 1984; $p 227$.

(14) Papp, H.; Hinsen, W.; Do, N. T.; Baerns, M. Thermochim. Acta 1984, $82,137$. different from faujasite ( $8 \AA$ ), the presence of the side pockets in the former (at low $\mathrm{Al} / \mathrm{Si}$ ratios) gives rise to a significantly higher heat of adsorption.

In summary, we have demonstrated that using a simple model potential computer simulations yield values for the heat of adsorption of a series of structurally rather different zeolites that are in good agreement with experimental values. Furthermore, computer simulations allow us to "see" where the methane molecule is located inside a zeolite. On the basis of this information we were able to suggest a simple explanation for the relatively high heat of adsorption of methane in mordenite. To our knowledge, no experimental study on the adsorption of methane in mordenite at several $\mathrm{Al} / \mathrm{Si}$ ratios has, as yet, been reported. It would be interesting to see whether the present prediction of the heat of adsorption is borne out by experiment.

In the present paper we have restricted our attention to the special case of methane in mordenite. This relatively simple case clearly illustrates how computer simulations can provide "microscopic" information about the arrangement of molecules in zeolites, and how this information may help us to predict the behavior of such zeolites. It should be stressed that the methods we have used are not limited to small rigid molecules. In this respect it is important to note that Mirodatos and Barthomeuf ${ }^{6}$ have reported on the effect of cage blocking by cations on the catalytic conversion of hydrocarbons in zeolites. Although the present simulations are limited to methane, they seem to corroborate the view put forward on the importance of the effects of blocking of the side pockets on the catalytic activity. Clearly, computer simulations can contribute to a better understanding of the behavior of more complex molecules inside a zeolite. Such understanding is crucial for the future design of tailor-made zeolites catalysts with ultrahigh selectivity.

Acknowledgment. It is a pleasure to thank R. A. J. Driessen, D. Frenkel, D. P. de Bruyn, M. F. M. Post, and R. A. van Santen for their contributions to this work.

\title{
Structure and Forces in Expanded Liquid Cesium
}

\author{
R. Winter, F. Hensel, * \\ Institute of Physical Chemistry, Philipps University, Hans-Meerwein-Strasse, D-3550 Marburg, FRG
}

T. Bodensteiner, and W. Gläser

Physik Department, TU München, D-8046 Garching, FRG (Received: September 19, 1988)

\begin{abstract}
The paper presents a neutron diffraction investigation of the static structure factor $S(Q)$ of liquid cesium expanded by heating toward conditions close to its liquid-vapor critical point. The experiment was designed to obtain the isothermal density derivative of $S(Q)$ which is related to the triplet correlation function. The data give the first information on the density-dependent changes in the interatomic forces as the metal-nonmetal transition is approached in the expanded liquid. In particular, the results provide direct experimental evidence for the limitation of the uniform fluid model.
\end{abstract}

\section{Introduction}

Over the past years a considerable amount of effort has been centered on the experimental $1^{1-5}$ and theoretical ${ }^{6-9}$ investigation of the behavior of liquid alkali metals expanded by heating toward the liquid-vapor critical point. The general object of this effort is to find out how the properties of metals vary with large changes in density, large enough to change the liquid metal into a nonmetal at large enough expansion. For the metal cesium specifically, the experimental evidence shows that the electrical conductivity $\sigma^{1,4}$ of the expanded liquid decreases greatly before a metal-nonmetal 